\title{
Clínica do Trabalho: Contribuições da Psicanálise para o Exercício Profissional
}

\author{
Victoria Ayelen Gomez ${ }^{1}$ \\ ${ }^{1}$ Universidade de Brasília, DF, Brasil. \\ Daniela Scheinkman Chatelard ${ }^{1}$ \\ ${ }^{1}$ Universidade de Brasília, DF, Brasil. \\ Tereza Cristina Cavalcanti Ferreira de Araujo ${ }^{1}$ \\ ${ }^{1}$ Universidade de Brasília, DF, Brasil.
}

Resumo: Este artigo tem como objetivo refletir sobre as contribuições da psicanálise para o exercício profissional da escuta do sofrimento no trabalho a partir da psicodinâmica do trabalho (PdT), da centralidade do trabalho e da escuta da palavra na clínica do trabalho. A PdT é uma clínica que se sustenta na descrição e no conhecimento das relações entre trabalho, sofrimento, prazer e saúde mental, e a centralidade do trabalho é fundamental para a atribuição de sentido e compreensão desse sofrimento no trabalho. A psicanálise propõe que o sujeito seja escutado e demarca um território importante para a palavra. Esse território se apresenta fundamental na escuta do sofrimento no trabalho, uma vez que ela se fundamenta nesse lugar. Sustenta-se a importância de uma lógica da singularidade de cada sujeito, ao considerar os significantes que marcam a história de cada trabalhador, mas sem deixar de ponderar os determinantes e os condicionantes sociais da produção desses sintomas. As contribuições da psicanálise para o exercício profissional na escuta do sofrimento no trabalho a partir da PdT se tornam fundamentais, uma vez que permitem considerar a singularidade daquele sujeito sem desconsiderar a organização do trabalho.

Palavras-chave: Sofrimento no Trabalho, Psicanálise, Psicodinâmica do Trabalho, Saúde do Trabalhador.

\section{Occupational Clinic: Contributions of Psychoanalysis to the Professional Practice}

\begin{abstract}
This article aims to reflect upon psychoanalytic contributions to the professional practice of listening to work-related suffering based on the Psychodynamics of Work (PdT), the centrality of work, and the listening of the word at the Occupational Clinic. The PdT is a clinical knowledge based on the description and knowledge of the relationships between work, suffering, pleasure, and mental health. In this context, the centrality of work is crucial for attributing meaning and understanding the suffering at work. Besides proposing that the individual should be listened to, the Psychoanalysis demarcates an important territory for the word - fundamental for listening to work-related suffering, since the word emerges within that place. In considering the signifiers of the individual history of each worker, such knowledge accounts for the importance of each subject singularity without excluding the social determiners and conditions in which these symptoms are produced. Thus, such process evinces the relevance of the contributions of psychoanalysis to the professional practice of listening to work-related suffering, for such theories consider the singularity of that subject without ignoring work organization.
\end{abstract}

Keywords: Suffering at Work, Psychoanalysis, Psychodynamics of Work, Worker's Health. 


\title{
Clínica del Trabajo: Contribuciones del Psicoanálisis al Ejercicio Profesional
}

\begin{abstract}
Resumen: Este artículo tiene como objetivo reflexionar sobre las contribuciones del psicoanálisis en el ejercicio profesional de la escucha del sufrimiento en el trabajo a partir de la psicodinámica del trabajo (PdT), la centralidad del trabajo y la escucha de la palabra en la clínica del trabajo. La PdT es una clínica que permite describir y conocer las relaciones entre trabajo, sufrimiento, placer y salud mental, y la centralidad del trabajo es fundamental para atribuir sentido y comprender ese sufrimiento. El psicoanálisis propone la escucha del sujeto y demarca un territorio importante para la palabra. Ese territorio es clave en la escucha del sufrimiento en el trabajo, ya que esta se fundamenta ahí. Se sustenta la importancia de una lógica singular de cada sujeto considerando los significantes que marcan la historia de cada trabajador sin dejar de considerar los determinantes y condicionantes sociales en la producción de esos síntomas. Las contribuciones del psicoanálisis al ejercicio profesional en la escucha del sufrimiento en el trabajo a partir de la PdT se vuelven fundamentales, ya que permiten considerar la singularidad de ese sujeto que sufre sin desconsiderar la organización del trabajo.
\end{abstract}

Palabras clave: Sufrimiento en el Trabajo, Psicoanálisis, Psicodinámica del Trabajo, Salud del Trabajador.

\section{Introdução}

Este texto tem como objetivo refletir sobre as contribuições da psicanálise para o exercício profissional na escuta do sofrimento no trabalho a partir da psicodinâmica do trabalho (PdT), da centralidade do trabalho e da escuta da palavra na clínica do trabalho. A PdT é uma clínica que se sustenta na descrição e no conhecimento das relações entre trabalho e saúde mental. Ela é uma disciplina teórica que tenta articular os resultados da investigação clínica da relação com o trabalho numa teoria do sujeito que abarca a psicanálise e a teoria social (Dejours, 2004). A abordagem desenvolve seus postulados a partir da ideia de que nos tipos de trabalho existe, inevitavelmente, uma brecha entre o trabalho prescrito e o real. As situações de trabalho são suscetíveis a acontecimentos inesperados, a anomalias de funcionamento, a incoerências organizacionais e a imprevistos decorrentes dos materiais e das ferramentas utilizadas, ou das relações com os colegas, chefes, subordinados, equipes e até com os clientes.

Dessa forma, considera-se que não existe um trabalho só de execução, de modo que a distância entre o prescrito e a realidade da situação (Dejours, 2008) é o próprio trabalhar, em uma acepção que indica que "trabalhar é constantemente ajustar, adaptar, reparar, arranjar" (Dejours, 2013, p. 3). Em outras palavras, o trabalho é aquilo que o trabalhador deve inventar e acrescentar às prescrições para que as coisas corram bem. Segundo Dejours e Deranty (2010), nesta abordagem, há um diálogo com a psicanálise, já que ela adota uma teoria de sujeito que considera a luta de forma constante contra o risco de doença mental ou alienação dele para poder manter seu equilibro. Isso é o que se concebe como "normalidade", isto é, uma solução de compromisso, um conflito entre sofrimento e defesa.

Nessa perspectiva, considera-se que as novas configurações sociais, culturais, políticas e econômicas incluem novos vínculos que compelem o sujeito à adequação aos mandatos e exigências do trabalho, o que gera sofrimento patogênico. Dessa forma, pesquisas atuais revelam (Duarte, 2014; Gama, Mendes, Araújo, Galvão, \& Vieira, 2016; Gómez, 2017) que o cenário atual no contexto do trabalho se mostra perverso, permeado por uma lógica de competição (Saraiv \& Mendes, 2014) e insegurança que desencadeia diversas manifestações relacionadas a essa conjuntura, como depressão e distúrbio osteomuscular relacionado ao trabalho (DORT) (Rocha, Mendes, \& Morrone, 2012), suicídios eideações suicidas (Dejours, 2008), situações de violência psicológica, física e simbólica (Gómez, 2017; Machado \& Kieling, 2018; Silva, Ribeiro, \& Machado, 2018), assim como de assédio 
moral e sexual. O cenário exige uma formação profissional que consiga dar conta dessas manifestações de sofrimento que considerem o mundo do trabalho.

Uma vertente da PdT é a clínica do trabalho, que permite, simultaneamente, pesquisa e intervenção no sofrimento relacionado ao trabalho. Essa vertente é definida como o espaço da fala e da escuta do sofrimento originado pela organização do trabalho, propiciando aos trabalhadores a criação de estratégias eficazes para afrontarem situações que provoquem sofrimento. Ela privilegia a fala não só por proporcionar um espaço de escuta, mas também por promover o exercício de falar e de escutar, buscando pôr a palavra em ação (Mendes \& Araújo, 2012).

A PdT também tem uma posição epistemológica que articula a hermenêutica, a psicanálise e a teoria da ação para compreender o sofrimento no trabalho e, consequentemente, atuar sobre ele. Essa abordagem teve desdobramentos conceituais e metodológicos a partir do uso original proposto por Dejours (1992). Os desenvolvimentos têm assumido uma configuração voltada para a prática da escuta clínica do sofrimento, vinculada à psicanálise de forma prioritária.

Como consequência dos desdobramentos que o método tem sofrido, diversos estudos investigam a maneira como as alterações feitas ao método dejourino - voltado para a prática da escuta clínica do sofrimento vinculada à psicanálise de forma prioritária - contribuem para uma escuta do sofrimento no trabalho (Gama et al., 2016). Esses desdobramentos incluíram grande avanço no que tange às técnicas e aos métodos de escuta. A partir desses avanços, foram abarcados atendimentos grupais e individuais que utilizam essa abordagem teórica. Os atendimentos individuais permitem relacionar aspectos da organização do trabalho com aqueles provenientes do sujeito, assim como possibilitam investigar de que maneira eles podem contribuir para uma escuta psicanalítica do sofrimento, de modo a produzir efeitos no posicionamento subjetivo dos sujeitos que participam dessa clínica, abrangendo também efeitos políticos (Mendes, 2015).

Assim, propôs-se a multiplicação do método clínico de escuta do sofrimento e a condução em clínica do trabalho que inclua uma escuta ao não dito e ao silenciado, buscando-se, de forma individual, a construção pelo sujeito de novas estratégias para lidar com o sofrimento e, assim, atribuir um novo sentido ao trabalho (Ghizone \& Mendes, 2014; Mendes \& Araújo, 2012; Souza \& Mendes, 2016). Nesse sentido, a condução em clínica do trabalho propõe uma leitura que aborde o sofrimento do trabalhador com base na lógica da singularidade de cada sujeito, considerando os significantes que marcam a história de cada trabalhador, sem, no entanto, negligenciar os determinantes e condicionantes sociais da produção desses sintomas na organização do trabalho. O elemento propositivo inclui pensar que a escuta do sofrimento originado no trabalho possibilita o estudo das relações de poder no ambiente de trabalho dentro das instituições, assim como das práticas institucionais, suas leis de funcionamento, cultura e campos de forças que se impõem aos indivíduos e que contribuem com o sofrimento e as patologias psicossociais do trabalho.

$\mathrm{O}$ artigo se propõe refletir sobre as contribuições da psicanálise para o exercício profissional na condução em clínica do trabalho. Para conseguir o objetivo proposto se desenvolveram eixos de análise, a saber: a) psicodinâmica do trabalho e centralidade do trabalho; b) psicanálise e a escuta da palavra na clínica do trabalho; e c) condução em clínica do trabalho.

A investigação do tema deu-se a partir de diversos estudos atualmente conduzidos em laboratórios de pesquisa de uma universidade pública do centro-oeste do Brasil. Assim, realizou-se levantamento bibliográfico a partir do site Google Acadêmico, com acesso a diversas bases de dados como SciELO e PEPsic, e do portal de periódicos Capes. A busca abrangeu mais do que os últimos cinco anos recomendados pela American Psychological Association (APA) na tentativa de achar mais estudos e reflexões teóricas que ajudassem na discussão das ponderações teóricas no laboratório de pesquisa.

\section{Psicodinâmica do trabalho e centralidade do trabalho}

A centralidade do trabalho é fundamental para atribuição de sentido e compreensão do sofrimento no trabalho (Duarte, 2014). Ele faz parte da vida do homem desde os primórdios, de modo que o homem vem modificando suas formas de trabalhar, o meio em que vive, seu viver e suas relações com a natureza (Freitas, 2013). O trabalho é, para Marx (1985), uma categoria central que concebe o homem enquanto ser social, já que é constituinte do sujeito que vive em sociedade, independentemente do modo de produção a que é submetido (Freitas, 2013). Assim, a centralidade do trabalho deve ser abordada considerando o processo de produção e reprodução material da vida em sociedade, em sua 
interação com a natureza e com os outros homens. Esse é um processo que implica a produção de nós mesmos - o homem -, a sociedade e as formas sociais.

A PdT é uma clínica que se sustenta na descrição e no conhecimento das relações entre trabalho e saúde mental. Na PdT se distinguem quatro formas em que o trabalho pode ser considerado central na formação da subjetividade: a centralidade do trabalho no que concerne à saúde mental do sujeito; à estrutura das relações entre homens e mulheres; à comunidade; e à teoria do conhecimento. Nesses termos, a PdT é constituída pela centralidade psicológica, de gênero, político-social e epistêmica do trabalho (Dejours \& Deranty, 2010). A tese da centralidade do trabalho é essencial para a PdT por considerar que, sendo o trabalho dirigido a outros, ele não apenas transforma o sujeito que trabalha, mas também produz sua realização no campo social (Freitas, 2013).

A interpretação da organização do trabalho é chave para a compreensão da maneira como entra em cena o jogo social; isto é, a organização do trabalho também é produto das relações sociais. A organização do trabalho é a divisão do trabalho, o conteúdo das tarefas, o sistema hierárquico, as modalidades de comando, as relações de poder e as questões de responsabilidade (Dejours, 1992). Trata-se da divisão do trabalho, em relação às formas da divisão das tarefas e modos operativos; e da divisão dos homens, em relação a como as tarefas são divididas, definidas e distribuídas entre os trabalhadores, a forma de como são operadas as fiscalizações, o controle, as ordens, a direção e a hierarquia, isto é, as relações de poder. Dessa forma, o "trabalhar" não é só uma experiência. Ele permite o surgimento do sofrimento afetivo no encontro do fracasso com o real - que marca não apenas o resultado ou o fim de um processo, mas também a subjetividade no trabalho (Dejours, 2004).

A questão da transformação do sofrimento em prazer tem relação com a identidade e com a construção de si mesmo. A existência de prazer no trabalho indica que isso é permitido pelos ganhos obtidos no registro da identidade. A atividade proporciona a oportunidade do encontro entre a identidade e $o$ real. O processo começa a partir do olhar do outro que possibilitará a transformação do sofrimento em prazer, o que exige que o reconhecimento entre em cena. $\mathrm{O}$ reconhecimento passa por julgamentos sobre o fazer e o trabalhar, mas não por parte daquele que trabalha (Dejours, 2004).
A partir do reconhecimento, consegue-se o fortalecimento e a manutenção de relações de cooperação, assim como na conjuração da violência entre homens e mulheres. Ele confere, ainda, um acréscimo àquele que se beneficia: o pertencimento a um coletivo, uma equipe e um ofício e, por isso, é um instrumento poderoso para conjurar a solidão social (Dejours, 2004). $\mathrm{O}$ reconhecimento desempenha um papel essencial na economia psíquica dos trabalhadores, de modo que não se possa construir sentido no trabalho sem reconhecimento. Ele exige um coletivo de trabalho e pode ser entendido em dois sentidos: tanto no âmbito da constatação da contribuição do trabalhador à organização do trabalho como no do reconhecimento por essa contribuição (Dejours, 2004).

O reconhecimento é um processo no qual o trabalhador vivencia gratidão pelo julgamento positivo do seu fazer, do seu esforço e do seu sofrimento, de modo que o reconhecimento assegura sua identidade. Ele pode ser proferido por seus pares, chefias, ou pelo grupo social, permitindo que o trabalhador se aproprie e ressignifique o seu sofrimento e, assim, se sinta mobilizado a fazer mudanças nos modos perversos de produção (Mendes, 2007).

Existe evidência de que o trabalho pode desestabilizar e causar doenças mentais (Duarte, 2014; Gama et al., 2016; Gómez, 2017), mas ele não gera apenas sofrimento e patologias; pode também ser fonte de prazer e se converter num mediador fundamental da economia psíquica na construção de saúde. Segundo Dejours e Deranty (2010), as estruturas que influenciam a saúde mental do trabalhador se caracterizam por dois processos: um em nível solipsista essencialmente individual - e o outro em nível social.

Dessa forma, a centralidade do trabalho e a relação subjetiva que se estabelece com o trabalho colaboram para que se compreenda como o trabalho pode levar por caminhos tão insuportáveis a ponto de alguns trabalhadores suicidarem-se nos próprios locais de trabalho. Tratar a questão da centralidade do trabalho indica que se deve começar a análise por aquilo que convoca a subjetividade na relação com o trabalho (Dejours, 2013): a mobilização subjetiva que se estabelece entre trabalho, sofrimento e prazer. Subjaz, assim, à mobilização subjetiva uma busca da identidade, pois o sujeito, além de executar a tarefa, quer dar vida ao trabalho e deixar sua marca. Esse é o processo pelo qual o sujeito se cria e pelo qual se evidencia a relação entre trabalho e identidade: 
a constituição e afirmação da identidade. Esse conceito fundamenta a concepção de trabalho para a psicodinâmica do trabalho e emerge diante das exigências e constrangimentos da organização do trabalho, isto é, do real do trabalho (Mendes \& Duarte, 2013).

A mobilização subjetiva no trabalho se compõe por dimensões indissociáveis como a inteligência prática, o espaço de discussão, a cooperação e o reconhecimento (Mendes \& Duarte, 2013; Duarte 2014). Dessa forma, trabalhar depende da experiência da alteridade e da vivência coletiva (Duarte, 2014).

\section{Psicanálise e a escuta da palavra na clínica do trabalho}

A psicanálise surgiu no início do século XX como uma disciplina que deu um novo estatuto ao sofrimento e os sintomas, trazendo a concepção deles como mensagens a ser decifradas. Além disso, ela originou um método de investigação do psiquismo e a explicação desse método que foi chamado de tratamento psicanalítico, mas que ultrapassou suas expectativas, tornando-se uma teoria da cultura (Menezes, 2010) e uma teorização que proporciona elementos para pensar os vínculos sociais. As elaborações psicanalíticas trouxeram uma especificidade em torno da infância que começou a repercutir o modo próprio como os psicanalistas ouvem os relatos de seus pacientes (Zavaroni, Viana, \& Celes, 2007). Freud considerava relevante não só aquilo que o paciente recordava, mas também a infância esquecida, algo da ordem do recalcado.

A compreensão dos primeiros anos de vida na constituição do psiquismo exigiu para Freud alto grau de movimentos de laboração. Segundo Zavaroni et al. (2007), ele deslizou da infância ao infantil como um caminho na construção teórica e, nesse construto, a fantasia ganhou destaque: a realidade psíquica adquiriu valor acima da realidade material. A fantasia se destaca na reconstrução do infantil em análise, e isso vai além do que foi visto, vivido ou ouvido na infância, abrangendo o que ficou gravado no psiquismo. Isso sugere que o infantil se faz presente na fala e nos modos como o analisando se põe em análise (Zavaroni et al., 2007). O infantil é atemporal e, neste ponto, o inconsciente foi e é o eixo pivô, referência estruturante).

A construção a posteriori do infantil não abandona a realidade histórica vivida (Zavaroni et al., 2007). O infantil se sustenta nessa realidade histórica que já não é a mesma, pois ela se desfigura. O texto "A interpretação dos sonhos" (Freud, 1900/1996a) proporcionou a compreensão sobre o lugar da infância na constituição do psiquismo (Zavaroni et al., 2007). Neste momento da obra do autor, Freud já se orientava pelo recalcado e isso o aproximava da reconstrução feita pelo paciente em sua fala. A fantasia se consolida como constituinte do psiquismo e se torna eixo central entender o infantil e como ele está presente no trabalho de análise.

Na publicação "Os três ensaios sobre a teoria da sexualidade" (Freud, 1905/1996b), aparece a noção da amnésia do infantil, remetendo a esse período tanto como esquecido quanto como determinante à luz da sexualidade. É nesse momento que Freud expressa não ser possível falar de extinção, mas sim de recalque. As conjecturas que desenvolveu nesse texto permanecem e são constantemente reavidos nos trabalhos posteriores, mas com o desenvolvimento de que o que permanece das fases infantis se reatualizam a posteriori. Assim, a relevância do infantil se mostra por todo o corpo teórico dos textos de Freud. O infantil liga conceitos como recalque, pulsão e inconsciente, e sua contemplação comparece como um recurso que possibilita uma posição do analista em relação a aquilo que escuta de seu paciente (Zavaroni et al., 2007).

Freud propõe, desde o início de sua experiência, que o paciente fosse escutado e demarca um território importante para a palavra (Macedo \& Falcão, 2005). Esse território se apresenta fundamental na clínica do trabalho, uma vez que ela se fundamenta nesse lugar. A história de vida do sujeito se entrelaça com a organização do trabalho e as modalidades de laço social.

O tempo da palavra como meio de acesso ao desconhecido em si mesmo e como tempo da escuta é uns dos pilares da psicanálise. Na situação entre alguém que fala e outro que escuta, se estabelece uma comunicação com mensagens cifradas e enigmáticas que demandam uma qualidade diferente de escuta para serem compreendidas. A palavra abre novas formas de compreensão do sofrimento (Macedo \& Falcão, 2005).

Na contemplação do inconsciente, a fala adquire o status de comunicar algo a mais, pois o sujeito comunica muito mais do que aquilo que se propôs. É por essa via que a clínica do trabalho atua, embora se estabeleça uma diferença fundamental: nela não se trabalha com associação livre. A escuta na clínica psicodinâmica do trabalho implica um saber-fazer e 
uma escuta específica que exige não apenas o conhecimento sobre o mundo do trabalho, mas também de uma noção de sujeito vinda da psicanálise. Atua-se com o pressuposto de que abrir um espaço para escutar o sofrimento no trabalho permite associar e colocar numa postura crítica as formas de gestão atuais que não permitem a expressão dos sentimentos (Gómez, Mendes, Chatelard \& Carvalho, 2016).

A escuta da palavra na clínica do trabalho vinculada à psicodinâmica do trabalho age com o pressuposto de que esse espaço contribui para politizar os sujeitos que expressam o que sentem, assim como permite tirar a banalidade da violência nas relações sócias no trabalho (Gómez et al., 2016). Dessa forma, Mendes e Araújo (2012) indicam que a clínica do trabalho é o espaço da fala e da escuta do sofrimento que se origina pela organização do trabalho. Nela se privilegia a fala no sentido de proporcionar um espaço de escuta, de promover o exercício de falar e de escutar numa tentativa de colocar a palavra em ação, isto é, a clínica prioriza a fala no sentido de buscar pôr a palavra em ação e de abrir oportunidades para se repensar o trabalho em suas dimensões visíveis e invisíveis, assim como de questionar a organização do trabalho e os laços sociais que os sujeitos constroem (Gómez et al., 2016; Mendes \& Araujo, 2012).

Entende-se que a fala implica eficiência no sentido de permitir processos de elaboração-perlaboração, possibilitando a passagem do espaço de discussão para o espaço de deliberação (Mendes \& Araújo, 2012). Entender a passagem desse processo exige remeter-se aos conceitos elaborados no escrito de Freud "Recordar, Repetir e Elaborar" (Mendes \& Araújo, 2012). Destaca-se, assim, o valor da psicanálise para a compreensão da dinâmica: trabalho, sujeito e ação em relação à escuta do sofrimento, à elaboração e à interpretação (Mendes \& Araújo, 2012). O fazer envolve conflitos, e a forma como ele afeta o sujeito é uma das ocupações da clínica (Gómez et al., 2016).

Nesta direção, a clínica psicodinâmica do trabalho é uma teoria clínica que tem como objeto central abranger a mobilização subjetiva no trabalho: o engajamento afetivo mediado pela palavra (Gómez et al., 2016). A escuta clínica contribui para promover a nomeação dos sintomas e inscrevê-los na ordem da palavra, o que possibilita elaborá-lo, bem como sugere um espaço que promova a mobilização subjetiva e o engajamento do trabalhador no encontro da identidade dele em seu fazer.
Existe uma especificação na atuação do clínico do trabalho. Para fazer a clínica, o profissional precisa desenvolver saberes sobre o mundo do trabalho e seu sofrimento. É essencial que o clínico, além de estudar e conhecer a teoria, tenha uma prática de escuta e de interpretação. Essa articulação com a teoria fortalece seu papel na busca da mobilização subjetiva (Mendes \& Araújo, 2012). Exige-se uma posição de clínico-pesquisador que implica que o clínico esteja em posição de escutar o material que o sujeito traz na perspectiva do inconsciente, de sua história singular, e dos processos contextuais-históricos e organizacionais. A escuta do sujeito do desejo supõe uma relação que se sustenta pela transferência que, por sua vez, produz um saber que está no sujeito e que ele não sabe que tem (Rosa, 2004). Dita escuta é alinhada a proposta de Gómez (2014), que indica a construção de uma escuta do sofrimento no trabalho que busque o resgate da subjetividade em um sentido contrário à lógica funcionalista, com preocupações adaptacionistas e produtivistas.

Gómez (2014) argumenta pela ideia de incorporar e trabalhar com os significantes usados pelo sujeito/ trabalhador, na medida em que isso permite ao analista estar atento ao repertório de significantes que ordenam cada sujeito. Os significantes que o sujeito usa são os que o organizam e o subordinam. Assim, se propõe como um recurso importante o silêncio, sem orientar, sem sugerir (Gómez et al., 2016).

Igualmente, na escuta da clínica do trabalho, considera-se que se deve atender ao que Lustoza (2009) aponta como as consequências do discurso capitalista no laço social. Esse discurso transforma a insatisfação constitutiva do desejo humano em uma insatisfação dirigida pelo mercado. A autora marca que o capitalismo se encontra voltado a fomentar nos sujeitos uma insatisfação constante que sempre está acompanhada pelo gozo de algum objeto descartável. A condição de haver laço social é o reconhecimento de que não somos capazes de fazer/dizer tudo sozinhos, mas sim de que, em função de nossa incompletude, precisamos nos dirigir ao outro.

Deve-se escutar o que não é dito no discurso, assim como a determinação dos não ditos dos enunciados sociais. Dessa forma, o campo transferencial permite que o clínico ocupe um lugar de suposto-saber: o sujeito supõe que fala para quem sabe sobre ele, mas nessa fala ele se escuta e se apropria do próprio discurso (Rosa, 2004). A noção de sujeito 
suposto-saber é necessária para que aquele que sofre possa se dirigir ao analista. Em seguida, o clínico não toma o lugar do saber, mas reconhece a importância dessa noção para o sujeito (Gómez et al.,2016).

A clínica não busca respostas e soluções de modo racional e objetivo, e conviver com essa frustação é fundamental para que ela ocorra (Mendes \& Araújo, 2012). A posição do clínico implica tornar-se um elo na escuta que possibilite a reumanização do sofrimento e deixar surgir a oportunidade de uma palavra (Mendes \& Araújo, 2012). A condução em clínica do trabalho e a escuta da palavra na clínica do trabalho objetivam argumentar a ideia de trabalhar a concepção de emancipação e de alteridade no sujeito, visto que se observa a demanda da organização do trabalho de alienar o sujeito por meio da adesão subjetiva, fazendo com que ele assuma posições e desejos que não lhe pertencem.

\section{Condução em clínica do trabalho e leitura política dos sintomas}

A psicanálise traz a ideia de que cada sintoma tem um sentido. O sintoma é um significado ou uma resposta do sujeito diante de algo e é uma forma paradoxal de satisfação do desejo que não é reconhecida pela consciência. Para a psicanálise, o sintoma é sintoma de algo e está no lugar de algo que não pode ser dito e que não encontrou possibilidades de ser representado (Silveira, Feitosa \& Palácio, 2014). O sintoma é um enigma a ser decifrado que se dirige ao outro e que porta a marca de uma satisfação substitutiva. No entanto, transformar a queixa inicial em um sintoma (enigma) só é possível pela instauração da transferência (Silveira et al., 2014).

Na clínica do trabalho, propõe-se, de acordo Silveira et al. (2014), uma leitura que aborde a saúde do trabalhador com base em uma lógica da singularidade de cada sujeito, considerando os significantes que marcam a história de cada trabalhador, mas sem deixar de ponderar os determinantes e condicionantes sociais da produção desses sintomas. A clínica almeja não atender a demanda do sujeito, mas sim colocá-lo frente ao enigma do seu desejo e, por conseguinte o clínico permitiria o surgimento do desejo como questão, apontando para o outro lugar em que ele se situava: o desejo do Outro (Silveira et al., 2014). É assim que o sujeito começa a perceber sua implicação naquilo de que vinha se queixando e o sintoma adquire o estatuto de uma pergunta: será que foi por isso que eu adoeci? (Silveira et al., 2014). Dessa forma, a clínica do trabalho espera colocar em crise o que é tido por "normal" quando a normalidade é um sintoma de violência e opressão (Pérrileux \& Mendes, 2015). Nessa perspectiva, impõe-se o desafio de aproveitar a crise como ocasião de abertura das controvérsias sobre os valores do trabalho. Trata-se de restaurar a voz de sujeitos críticos e de emergir a possibilidade de uma palavra.

O dispositivo clínico é operado pela palavra como um revelador, e uma questão fundamental da clínica é constituir o mal-estar em sintoma de forma a proceder de tal maneira que o sintoma possa ser dito (Pérrileux \& Mendes, 2015). Os autores apontam que na clínica do trabalho é fundamental buscar confrontar a frustração da impotência e assumir sua condição de desamparo, pois, muitas vezes, a relação onipotência-impotência é acessada em função de uma perversa organização do trabalho, com falsas promessas de reconhecimento do trabalho e ao mesmo tempo uma desqualificação constante. As demandas que a organização do trabalho desenha são pautadas com base na ideologia da excelência, que não oferece espaço para as falhas do humano e que produz subjetividades que se desestabilizam ante a impotência do confronto com o real.

Por outro lado, reconhece-se que a maneira de ser afetado e a maneira de falar disso é sempre singular; ao mesmo tempo em que os sintomas falam, também, das condições contemporâneas de trabalho (Pérrileux \& Mendes, 2015). A clínica do trabalho testemunha que na origem das formações sintomáticas, as causas podem encontrar-se na organização do trabalho e na opressão exercida pelas relações sociais (Pérrileux \& Mendes, 2015). Nesse caminho, considera-se importante que um clínico não transforme o problema social em um problema pessoal do sujeito.

Nesta perspectiva, a clínica não consiste em optar pelo singular em detrimento do geral, nem pela realidade fantasmática em detrimento da realidade histórica (Pérrileux \& Mendes, 2015), mas sim em manter os polos em tensão para poder circular entre eles. Pérrileux e Mendes (2015) colocam que a questão do sintoma orienta as escolhas em clínica do trabalho. Nesse sentindo, advertem da possibilidade de se tentar a dissolver a singularidade do mal-estar com uma explicação de suas causas junto à organização do trabalho ou, pelo contrário, procurar dar ênfase à realidade psíquica (fantasias e conflitos inconscientes) na realidade histórica (história das relações de trabalho). 
Por tanto, a clínica do trabalho objetiva certa virada da situação, interpelando ao sujeito uma ruptura com os sintomas. Essa ruptura depende da escuta política dos sintomas pelo clínico, que viabiliza uma saída de uma posição subjetiva de assujeitamento para a possível alteridade (Pérrileux \& Mendes, 2015).

A condução em clínica do trabalho propõe uma leitura que aborde a saúde do trabalhador com base em uma lógica da singularidade de cada sujeito, considerando os significantes que marcam a história de cada trabalhador, mas sem deixar de ponderar os determinantes e condicionantes sociais e da organização do trabalho da produção desses sintomas. A palavra e o processo que implica a fala e a escuta entre o sujeito e o clínico-pesquisador são privilegiados.. Isso exige uma qualificação teórico-metodológica que articule uma teoria do sujeito e uma teoria social em uma condução orientada na escuta do outro (Souza \& Mendes, 2016). Dessa forma, trata-se de uma escuta ao não dito e ao silenciado, buscando construir novas estratégias para lidar com o sofrimento e, assim, atribuir um novo sentido ao trabalho (Ghizone \& Mendes, 2014; Mendes \& Araújo, 2012; Souza \& Mendes, 2016).

Outro aspecto importante se relaciona com considerar que o sofrimento pode não ter um objeto claro e envolver para algumas pessoas um apego ou uma resistência em se livrar dele. Então, é importante que se compreenda a função do sintoma na vida do sujeito e a repetição dele (Mendes, 2015). Assim, Mendes (2015) esclarece que, quando o sujeito abre mão do seu sintoma, o que fica nesse lugar é a própria falta. A angústia, a insegurança e o medo vão fazer com que esse sujeito não queira abandonar aquele sintoma. A autora indica que talvez a ideia da clínica não seja eliminá-los, mas sim entender tanto a história deles como a função que eles exercem e qual outra trajetória ou destino eles podem ter.

O processo clínico começa na falta inscrita na fala e na busca de que a palavra tome forma para que, uma vez nomeada, possa se exercer uma ação. É um anseio que gera uma demanda, que para o clínico é a representação do acessível e analisável do desejo (Mendes, 2014). É uma escuta que, inevitavelmente, exige uma compreensão do sofrimento no trabalho e suas particularidades no encontro com o real. A demanda inicial deve ser aprofundada e dará início a discussão que envolve a queixa, o sintoma e o desejo (Mendes, 2014). O processo clínico se orienta com o pressuposto de que a demanda nunca será satisfeita, mas que, enquanto mais se trabalha, mais vazio se experimenta. O clínico deve saber trabalhar com a demanda que os trabalhadores trazem, pois é a partir dela que será propiciada a elaboração dos conflitos.

É através da transferência que o sujeito sente confiança e quer falar. A transferência ocorre quando o sujeito admite o que se passa com ele de forma contrária a uma postura onipotente (Mendes, 2014). Ela é um afeto que se instala na fala e por meio do qual o sujeito se sente reconhecido, encontrando uma palavra que vai ao encontro de sua identidade. Assim, quando o sujeito se manifesta, se abrem possibilidades de ele recompor uma existência que lhe permita sair dos seus impasses repetitivos e, de alguma forma, se ressingularizar. A ideia é que o clínico seja um elo na cadeia de escuta que implique na reumanização do sofrimento e no surgimento de uma palavra capaz de ressignificar o sofrimento e, a partir daí, mobilizar-se (Mendes, 2014).

Para Rosa (2004), a escuta do sujeito supõe uma relação sustentada pela transferência, que, por sua vez, produz um saber que está no sujeito e que ele não sabe que tem. Escutar o sofrimento não significa eliminá-lo, mas sim criar uma nova posição diante do seu sentido. A singularidade do sujeito convoca a singularidade do clínico, convocação essa permitida pela transferência que sucinta a construção de laços afetivos (Mendes \& Oliveira, 2014). Assim, compreender a função do sintoma convida o clínico do trabalho à escuta atenta do manifesto no sofrimento-sofrimento revelado no encontro entre o clínico e o trabalhador e manifesto pelo discurso do sujeito. Essa relação, que possibilita a construção do discurso, é possível pelo estabelecimento da transferência como prevista na dinâmica analítica (Gama et al., 2016).

Segundo Souza e Mendes (2016), a interpretação é o processo que dá forma ao que é vivido e trazido pelos trabalhadores. Ela é colocar significado à fala tentando relacionar o prazer, o sofrimento e as relações de poder. Trata-se de uma experiência que articula os referenciais teóricos e metodológicos do clínico, considerando o sujeito e o mundo do trabalho. Portanto, Mendes (2014) indica que o clínico do trabalho deve orientar sua interpretação na perspectiva de contribuir o surgimento de novos temas, assim como a vontade de continuar falando. Quando se segue uma interpretação alinhada e "correta", a fala e o desejo de se expressar se mantém. O contrário implica no esfriamento e nas resistências. A interpretação oferece uma trajetória ao sintoma e permite que ele passe pela queixa e pela demanda. 
Nesse sentido, o sintoma revela uma verdade particular ao sujeito e estudá-lo ajuda o sujeito a atravessar a queixa e vencer o mórbido através da percepção da falta no outro. É uma perspectiva não de libertação dos sintomas, mas sim de compreensão da implicação do sujeito nesse quadro (Gama et al., 2016).

Neste ponto, interessa a ideia do falar-ser enquanto efeito de linguagem sobre o sujeito e sobre a realidade fundada por um discurso (Chatelard, 2016), isto é, interessa a ideia de um discurso entendido como laço social. Na leitura de Chatelard (2016), o sujeito da psicanálise existe por causa de um sintoma que faz dele um sujeito que sofre e que falha. Assim, o autor coloca a questão de uma incógnita, de um enigma que o sujeito tem e para qual busca sentido na clínica. Eis que o trabalho de transferência é uma operação do sujeito que consiste no desenvolvimento de uma incógnita (Chatelard, 2016) por meio da interpretação. O discurso do analista (clínico) é o laço social criado por uma análise (escuta clínica) que possibilita a implicação do sujeito, pelo dizer, no gozo que seu sintoma denuncia (Chatelard, 2016). Assim, a interpretação incide sobre a incógnita que ela revela.

A interpretação busca facilitar o processo de perlaboração. Isso se sucede quando é propiciada a reintegração pelo trabalhador de sua história de vida em uma dimensão que ultrapasse os limites individuais (Mendes \& Araujo, 2012). É um processo que, segundo Freud (1914/1996c), não é de curso calmo. Existe uma relação com a transferência e a repetição; sendo o fenômeno da transferência um fragmento da repetição do passado esquecido. Dessa forma, o clínico do trabalho precisa ajudar esse sujeito que o procura a enfrentar sua falta, apesar da inserção em um mundo laboral que apregoa o discurso da completude. Neste momento, abre-se a possibilidade para o clínico de trabalhar com o sujeito novas abordagens para o enfrentamento do mundo do trabalho, seja por intermédio da construção de defesas que podem proporcionar força política para o coletivo do trabalho, seja pelo investimento sublimatório, que tanto pode ocorrer em ações no local de trabalho quanto fora dele (Gama et al., 2016).

\section{Considerações finais}

Este texto teve como objetivo refletir sobre as contribuições da psicanálise para o exercício profissional na escuta do sofrimento no trabalho a partir da psicodinâmica do trabalho (PdT), a centralidade do trabalho, e a escuta da palavra na clínica do trabalho.
A PdT é uma clínica que se sustenta na descrição e no conhecimento das relações entre trabalho e saúde mental; e é uma disciplina teórica que tenta articular os resultados da investigação clínica da relação com o trabalho numa teoria do sujeito, que abarca a psicanálise e a teoria social (Dejours, 2004).

Nesta perspectiva, argumenta-se que atuar com o pressuposto da centralidade do trabalho é fundamental para atribuição de sentido e compreensão do sofrimento no trabalho (Duarte, 2014). A relação subjetiva que se estabelece com o trabalho, a partir da centralidade, colabora para que se compreenda como o trabalho pode levar por caminhos tão insuportáveis a ponto de alguns trabalhadores suicidarem-se nos próprios locais de trabalho. Assim, tratar a questão da centralidade do trabalho indicou também que se deve começar pela análise daquilo que convoca a subjetividade na relação com o trabalho (Dejours, 2013).

Igualmente, se argumentou que é imprescindível que se escute o sujeito que sofre em relação ao trabalho. Freud propõe desde o início de sua experiência que o paciente fosse escutado, demarcando um território importante para a palavra (Macedo \& Falcão, 2005). Esse território se apresenta fundamental na clínica do trabalho, uma vez que ela se fundamenta nesse lugar. Essa é uma escuta que contempla a história de vida do sujeito que se entrelaça com a organização do trabalho e as modalidades de laço social. Nesse sentido, abrir um espaço para escutar o sofrimento no trabalho permite associar e colocar numa postura crítica as formas de gestão atuais que não permitem a expressão dos sentimentos (Gomez et al., 2016).

Consideramos que os pilares da psicanálise contribuem para o exercício profissional nessa escuta do sofrimento. Assim, a escuta na clínica psicodinâmica do trabalho implica um saber-fazer e uma escuta específica que exige não apenas o conhecimento sobre o mundo do trabalho, mas também o de uma noção de sujeito vinda da psicanálise.

A clínica privilegia a fala no sentido de buscar pôr a palavra em ação e abrir oportunidades de repensar o trabalho em suas dimensões visíveis e invisíveis, assim como de questionar a organização do trabalho e os laços sociais que os sujeitos constroem (Gómez et al., 2016; Mendes \& Araújo, 2012). Para isso, o profissional precisa desenvolver saberes sobre o mundo do trabalho e o sofrimento. Deve-se escutar o que não é dito no discurso, assim como a determinação dos não ditos dos enunciados sociais. 
Na escuta do sofrimento no trabalho, propõe-se uma leitura que aborde a saúde do trabalhador com base em uma lógica da singularidade de cada sujeito, considerando os significantes que marcam a história de cada trabalhador, mas sem deixar de ponderar os determinantes e condicionantes sociais da produção desses sintomas. Nesse sentido, as contribuições da psicanálise para o exercício profissional na escuta do sofrimento no trabalho se tornam fundamentais, uma vez que permitem considerar a singularidade daquele sujeito sem desconsiderar a organização do trabalho.

\section{Referências}

Chatelard, D. S. (2016). Do trabalho de transferência à transferência de trabalho: Uma transmissão. Trabalho (En) Cena, 1(1), 75-83.

Dejours, C. (1992). A loucura do trabalho: Estudo de psicopatologia do trabalho. Cortez.

Dejours, C. (2004). Subjetividade, trabalho e ação. Produção, 14(3), 27-34. http://dx.doi.org/10.1590/ S0103-65132004000300004

Dejours, C. (2008). A avaliação do trabalho submetida a prova do real - Críticas aos fundamentos da avaliação. In L. L. Sznelwar, \& F. Mascia (Orgs.), Trabalho, tecnologia e organização (pp. 31-90). Blucher.

Dejours, C. (2013). A sublimação, entre sofrimento e prazer no trabalho. Revista Portuguesa de Psicanálise, 33(2), 9-28.

Dejours, C., \& Deranty, J. P. (2010). The Centrality of Work. Critical Horizons, 11(2), 167-180. http://dxdoi:10.1558/ crit.v11i2.167

Duarte, F. S. (2014). Dispositivos para a escuta clínica do sofrimento no trabalho: Entre as clínicas da cooperação e das patologias [Dissertação de mestrado, Universidade de Brasília]. Repositório Institucional da UnB. https://repositorio.unb.br/handle/10482/15885

Freitas, L. G. (2013). Centralidade do Trabalho. In F. Vieira, A. M. Mendes, \& A. R. Merlo. (Orgs.), Dicionário Crítico de Gestão e Psicodinâmica do Trabalho (pp. 77-81). Juruá.

Freud, S. (1996a). A interpretação dos sonhos. In S. Freud, Obras psicológicas completas de Sigmund Freud: Edição standard brasileira (Vol. 4-5). Imago. Trabalho original publicado em 1900

Freud, S. (1996b). Três ensaios sobre a teoria da sexualidade. In S. Freud, Obras psicológicas completas de Sigmund Freud: Edição standard brasileira. (Vol. 7, pp. 119-229). Imago. Trabalho original publicado em 1905

Freud, S. (1996c). Recordar, repetir e elaborar (novas recomendações sobre a técnica da psicanálise II). In S. Freud, Obras psicológicas completas de Sigmund Freud: Edição standard brasileira (Vol. 7, pp. 163-171). Imago. Trabalho original publicado em 1914

Gama, L. P., Mendes, A. M., Araújo, J. P., Galvão, M. G. A., \& Vieira, F. O. (2016). Ressignificação do sofrimento: Clínica do trabalho em um hospital escola. Laborativa, 5(1), 38-63.

Ghizone, L. D., \& Mendes, A. M. (2014). Dispositivos para uma escuta clínica do sofrimento no trabalho dos catadores de materiais recicláveis. Contextos Clínicos, 7(1), 15-26. http://dx.doi.org/10.4013/ctc.2014.71.02

Gómez, O. J.J. (2014). O mal-estar subjetivo derivado da fragmentação do trabalho [Tese de doutorado, Universidade de São Paulo]. Biblioteca Digital Teses e Dissertações USP. https://teses.usp.br/teses/disponiveis/47/47134/ tde-18032015-112739/pt-br.php

Gómez, V. A. (2017). Desamparo e sofrimento no trabalho bancário: Um estudo de caso em clínica do trabalho [Dissertação de mestrado, Universidade Nacional de Brasília]. Repositório Institucional da UnB. https://repositorio.unb.br/handle/10482/23609

Gómez, V.A., Mendes, A. M., Chatelard, D. S., \& Carvalho, I. S. (2016). A palavra como laço social na clínica psicodinâmica do trabalho. Contextos Clínicos, 9(2), 253-264. https://doi.org./10.4013/ctc.2016.92.10

Lustoza, R. Z. (2009). O discurso capitalista de Marx a Lacan: Algumas consequências para o laço social. Ágora, 12(1), 41-52. http://dx.doi.org/10.1590/S1516-14982009000100003

Macedo, M. M. K., \& Falcão C. N. B. (2005). A escuta na psicanálise e a psicanálise da escuta. Psychê, 10(15), 65-76.

Machado, P.A. \& Kieling, M. J. (2018). Assédio moral no judiciário: Prevalência e repercussões na saúde dos trabalhadores. Revista Psicologia Organizações e Trabalho, 18(2), 346-353. https:// dx.doi.org/10.17652/rpot/2018.2.13516 
Marx, K. (1985). O capital: Crítica da economia política. Difel.

Mendes, A. M. (2007). Psicodinâmica do Trabalho: Teoria, método e pesquisas. Casa do Psicólogo.

Mendes, A. M. (2014). Escuta analítica do sofrimento e o saber-fazer do clínico do trabalho. In A. M. Mendes, R. Dutra de Moraes, \& C. Merlo (Orgs.), Trabalho e sofrimento (pp. 65-80). Juruá.

Mendes, A. M. (2015, Abril). Meu trabalho me adoece? Entrevista realizada com Ana Magnólia Bezerra Mendes. Encena Saúde Mental. http://encenasaudemental.net/comportamento/entrevista/meu-trabalho-me-adoece

Mendes, A. M., \& Araújo, K. R. (2012). Clínica da psicodinâmica do Trabalho: O Sujeito em ação. Juruá.

Mendes, A. M. \& Duarte F. (2013). Mobilização Subjetiva. In F. O. Vieira, A. M. Mendes A. M., \& A. R. C. Merlo (Orgs.), Dicionário crítico de gestão e psicodinâmica do trabalho (pp. 259-262). Juruá.

Menezes, L. S. A. (2010). Um olhar psicanalítico sobre a precarização do trabalho: Desamparo, pulsão de domínio e servidão [Tese de doutorado, Universidade de São Paulo]. Biblioteca Digital Teses e Dissertações USP. https://www.teses.usp.br/teses/disponiveis/47/47131/tde-19102010-120022/pt-br.php

Périlleux, T., \& Mendes, A. M. (2015). O enigma dos sintomas: Proposição para uma escuta psicanalítica e política do sofrimento no trabalho. Revista Trivium: Estudos Interdisciplinares, 1(1), 61-73. http://dx.doi.org/ 10.18370/2176-4891.2015v1p61

Rocha, S. R. A., Mendes, A. M., \& Morrone, C. F. (2012). Sofrimento, distúrbios osteomoleculares e depressão no contexto de trabalho: Uma abordagem psicodinâmica. Estudos e Pesquisas em Psicologia, 12(2), 379-394.

Rosa, M. D. (2004). A pesquisa psicanalítica dos fenômenos sociais e políticos: Metodologia e fundamentação teórica. Revista Mal-Estar e Subjetividade, 4(2), 329-348.

Saraiva, L. A. S., \& Mendes, A. M. (2014). Consultores de mercado, sua lógica perversa de gestão e normopatia. Polis e Psique, 4(1), 128-145. https://doi.org/10.22456/2238-152X.42769

Silva, L., Ribeiro, S. \& Machado, B. B. (2018). “A gente está sempre com a guilhotina no pescoço”: Precariedade e violência no trabalho docente. Acta Scientiarum:Education, 40(1), 3-11. https://doi.org/10.4025/actascieduc.v40i1.37657

Silveira, L. C., Feitosa, R. M. M., \& Palácio, P. D. B. (2014). A escuta do sofrimento psíquico relacionado ao trabalho: Contribuições da psicanálise para o cuidado em saúde. Psicologia em Revista (Belo Horizonte), 20(1), 19-33. https://doi.org/10.5752/P.1678-9523.2014v20n1p19

Souza, R. G., \& Mendes, A. M. (2016). Ressignificação do TEPT a partir da clínica psicodinâmica do trabalho. Revista Guillermo de Ockham, 14(2), 73-82. https://doi.org/10.21500/22563202.2424

Zavaroni, D. M. L., Viana, T. C., \& Celes, L. A. M. (2007). A constituição do infantil na Obra de Freud. Estudos de Psicologia, 12(1), 65-70. http://doi.org/10.1590/S1413-294X2007000100008

\section{Victoria Ayelen Gomez}

Doutoranda em Psicologia Clínica e Cultura no Programa de Pós-Graduação em Psicologia Clínica e Cultura do Instituto de Psicologia da Universidade de Brasília (UnB), Brasília - DF. Brasil.

E-mail: victoria.ayelen.gomez@gmail.com

(1) https://orcid.org/0000-0001-5753-6429

\section{Daniela Scheinkman Chatelard}

Professora associada no Programa de Pós-Graduação em Psicologia Clínica do Instituto de Psicologia na UnB, Brasília - DF. Brasil.

E-mail: dchatelard@gmail.com

(1) https://orcid.org/0000-0002-7925-573X

Tereza Cristina Cavalcanti Ferreira de Araujo

Professora titular da UnB, Brasília - DF. Brasil.

E-mail:araujotc@unb.br

(1) https://orcid.org/0000-0002-5204-8124 
Endereço para envio de correspondência:

Universidade de Brasília, Instituto de Psicologia, Campus Universitário Darcy Ribeiro. Laboratório de Psicanálise dos Processos de Subjetivação. Asa Norte. CEP 70910-900. Brasília - DF. Brasil.

Recebido 18/04/2018

Aceito 16/10/2018

Received 04/18/2018

Approved 10/16/2018

Recibido 18/04/2018

Aceptado 16/10/2018

Como citar: Gomez, V. A., Chatelard, D. S., \& Araujo, T. C. C. F. (2021). Clínica do Trabalho: Contribuições da psicanálise para o exercício profissional. Psicologia: Ciência e Profissão, 41, 1-12. https://doi.org/10.1590/ 1982-3703003192735

How to cite: Gomez, V. A., Chatelard, D. S., \& Araujo, T. C. C. F. (2021). Occupational Clinic: Contributions of psychoanalysis to the professional practice. Psicologia: Ciência e Profissão, 41, 1-12. https://doi.org/10.1590/ 1982-3703003192735

Cómo citar: Gomez, V. A., Chatelard, D. S., \& Araujo, T. C. C. F. (2021). Clínica del Trabajo: Contribuciones del psicoanálisis al ejercicio profesional. Psicologia: Ciência e Profissão, 41, 1-12. https://doi.org/10.1590/ 1982-3703003192735 